\title{
The Use of the Tip Potential of Glass Microelectrodes in the Determination of Low Cell Membrane Potentials *
}

\author{
Dieter F. Hülser and Dennis J. Webb \\ Max-Planck-Institut für Virusforschung, Abteilung für Physikalische Biologie, Tübingen
}

Received March 25, 1973

\begin{abstract}
Summary. The tip potential of Ling-Gerard glass microelectrodes changes upon insertion into cells and thus impedes the determination of the actual membrane potential. The lower the membrane potential of a cell, the larger will be the error due to this tip potential. However, as is demonstrated, a relationship exists between the tip potential of the electrode and the measured potential difference, which allows the determination of the membrane potential of a particular cell type by linear regression. This method showed that resting lymphocytes had no membrane potential, whereas for the slime mould Dictyostelium discoideum a membrane potential of about $-9 \mathrm{mV}$ could be calculated.
\end{abstract}

\section{Introduction}

Most living cells generate an easily demonstrable transmembrane potential, the cell interior being negative relative to the extracellular fluid. This membrane potential can be determined using fine-tipped Ling-Gerard glass microelectrodes [11]. Since Adrian [1] demonstrated that membrane potential measurements were influenced by an electrode-specific junction potential, the so-called tip potential, glass microelectrodes have generally been selected for low tip potentials within a certain ohmic resistance range. Such a selection reduces the error in the determination of the cell membrane potential. However, the lower the membrane potential of a cell, the larger will be the error due to the tip potential.

In this communication we demonstrate how this problem can be overcome. As is already known, the tip potential of a glass microelectrode changes upon insertion of its tip into a cell by a constant factor [1, 3, 14]. This phenomenon can be employed for the determination of the real membrane potential of a particular cell type. Using a large number of glass microelectrodes having a wide range of tip potentials, a linear relationship with the measured potential differences is found. Assuming that the real membrane potential will be measured by an electrode with no tip potential, it would then be given by the intercept of the calculated regression line at zero tip potential.

\section{Materials and Methods \\ Electrical Set-Up}

Ling-Gerard microelectrodes were prepared from glass capillaries (Corning Pyrex glass 7740/234400) using a vertical pipette puller (David Kopf Instruments,

* Dedicated to Prof. Dr. Dr. h.c. mult. B. Rajewsky on the occasion of his 80th birthday. 
Model $700 \mathrm{C}$ ). The microelectrodes were filled either with $3 \mathrm{M} \mathrm{KCl}$ or physiological $\mathrm{NaCl}$ solution. $2 \mathrm{mM} \mathrm{K}$ citrate was added to the $3 \mathrm{M} \mathrm{KCl}$ solution to provide electrodes with lower tip potentials [13]. Electrodes were only used after a $48 \mathrm{~h}$ aging period. The microelectrode was connected via a calomel electrode to a negative capacitance electrometer (Keithley Mod. 605). An indifferent calomel electrode closed the circuit and was connected to the bath solution either by a Ringer-agar bridge or by another glass microelectrode. A pen recorder (Graphirac, Sefram) was used to register the measured potential differences. For further details see $[8]$.

\section{Cell Cultures}

\section{Lymphocytes}

The cells were obtained from bovine lymph nodes [6] and cultivated in a modified Eagle-Dulbecco medium [4]. To facilitate electrode insertion, the lymphocytes were immobilized by an agar gelatine film in a plastic Petri dish (Falcon or Greiner) and covered with Eagle Dulbecco medium $+10 \%$ calf serum. This procedure did not influence the viability of the cells [10].

\section{Dictyostelium Discoideum}

The ax-2 strain of the cellular slime mould Dictyostelium discoideum was grown in suspension culture in axenic medium $[5,15]$ up to a density of approximately $10^{7}$ cells $/ \mathrm{ml}$. After washing the cells three times in $16.7 \mathrm{mM}$ phosphate buffer $(p H 6.0)$, they were resuspended in the buffer and seeded into plastic Petri dishes. The cells normally adhered to the bottom and could be easily impaled with the microelectrodes.

\section{Results and Discussion}

The tip potential is defined as the potential difference which is observable in a closed circuit upon breakage of the electrode tip. Microelectrodes filled with $3 \mathrm{M} \mathrm{KCl}$ have a tip potential which is always negative relative to the cell culture medium in which the tip is immersed. Such electrode tip potentials can achieve values greater than $40 \mathrm{mV}$. The potential of a circuit containing a broken electrode can be regarded as the zero potential; in this state only potentials which remain constant during an experiment should be present $[2,3,12]$. The potential difference appearing upon introduction of an intact microelectrode can be taken as an indication for the tip potential of this new electrode; however, the zero potential is sometimes found to vary by 1 to $2 \mathrm{mV}$ when different electrodes with broken tips are introduced into the same circuit. Therefore, measurements were only included in the analysis when the potential baseline remained stable, allowing the determination of the real tip potential at the end of an experiment.

The tip potential and resistance of a glass microelectrode are both influenced by the ionic strength of the solution in which the tip is immersed. This is demonstrated in Table 1 for an electrode filled with $3 \mathrm{M} \mathrm{KCl}+2 \mathrm{mM} \mathrm{K}$ citrate immersed in different $\mathrm{KCl}$ concentrations (see also [8]).

A representative series of potential difference measurements in resting lymphocytes using one microelectrode is shown in Fig. 1. Starting on the left, the zero potential line can be seen (z). After replacing the broken electrode with an intact 
Table 1. Changes in the tip potential and resistance of a Ling-Gerard glass microelectrode filled with $3 \mathrm{M} \mathrm{KCl}+2 \mathrm{mM} \mathrm{K}$ citrate when immersed into culture medium and $\mathrm{KCl}$ solutions of different concentration

\begin{tabular}{llcccc}
\hline & $\begin{array}{l}\text { Eagle- } \\
\text { Dulbeco- } \\
\text { Medium }\end{array}$ & $0.003 \mathrm{M} \mathrm{KCl}$ & $0.03 \mathrm{M} \mathrm{KCl}$ & $0.3 \mathrm{M} \mathrm{KCl}$ & $3 \mathrm{M} \mathrm{KCl}$ \\
& -7.5 & -60 & -20 & -2.2 & +2.5 \\
Tip potential $[\mathrm{mV}]$ & -60 & 84 & 50 & 24 \\
\hline Electrode resistance $[\mathrm{M} \Omega]$ & 65 & 160 & & & \\
\hline
\end{tabular}
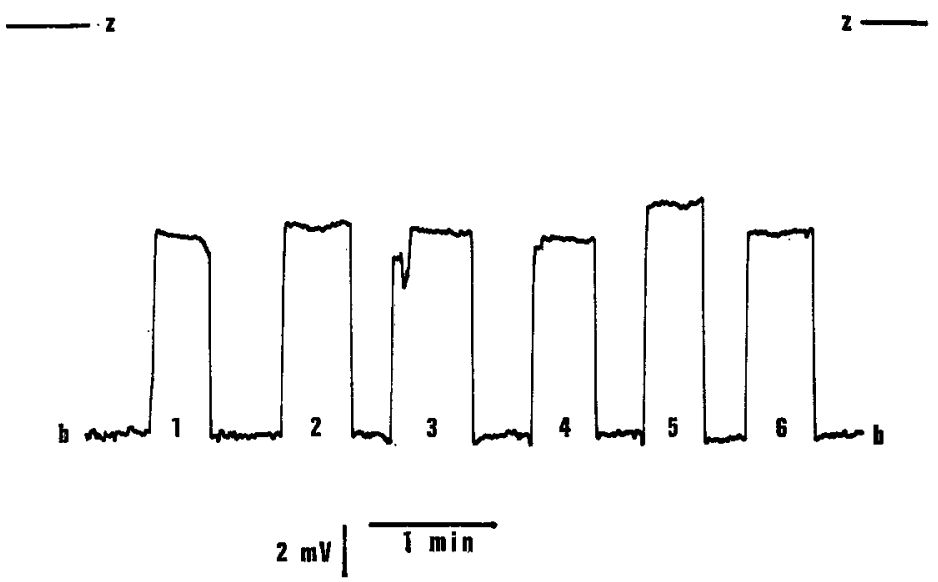

Fig. 1. Determination of the tip potential of a glass microelectrode and potential difference measurements in resting lymphocytes. z: zero potential obtained with a broken electrode; $b$ : baseline for the potential difference measurements in the cells obtained with an intact electrode; $z-b$ : represents the negative electrode tip potential $(=16 \mathrm{mV})$; 1-6: measurements of positive potential differences upon insertions of the electrode into different lymphocytes (about $8 \mathrm{mV}$ )

$3 \mathrm{M} \mathrm{KCl}$ electrode, a potential difference of $-16 \mathrm{mV}$, equal to the tip potential, is measured (b). This potential level is the baseline for the measurements with this electrode, i.e., potentials relative to this baseline will be recorded after inserting the electrode into a cell. Subsequent impalement of lymphocytes gives rise to potential differences of $+8 \mathrm{mV}$ indicated by numbers 1 to 6 . When the electrode tip is broken at the end of the measurements, the same zero potential is again registered (z). Fig. 2 shows the results of similar experiments in which more than a thousand potential difference measurements were made with 115 electrodes. The solid line is the computed regression line (by an IME $86 \mathrm{~S}$ computer, programme No. $63131 \mathrm{~S}$ ) which gives the relationship between the tip potential (TP) and the recorded potential difference $(\mathrm{PD})$ expressed by the equation:

$$
\mathrm{PD}=-0.55 \cdot \mathrm{TP}+0.009 \text {. }
$$

The high significance of this relationship is shown by the correlation coefficient of -0.96 . The intercept $(0.009)$ given by regression analysis indicates that resting 


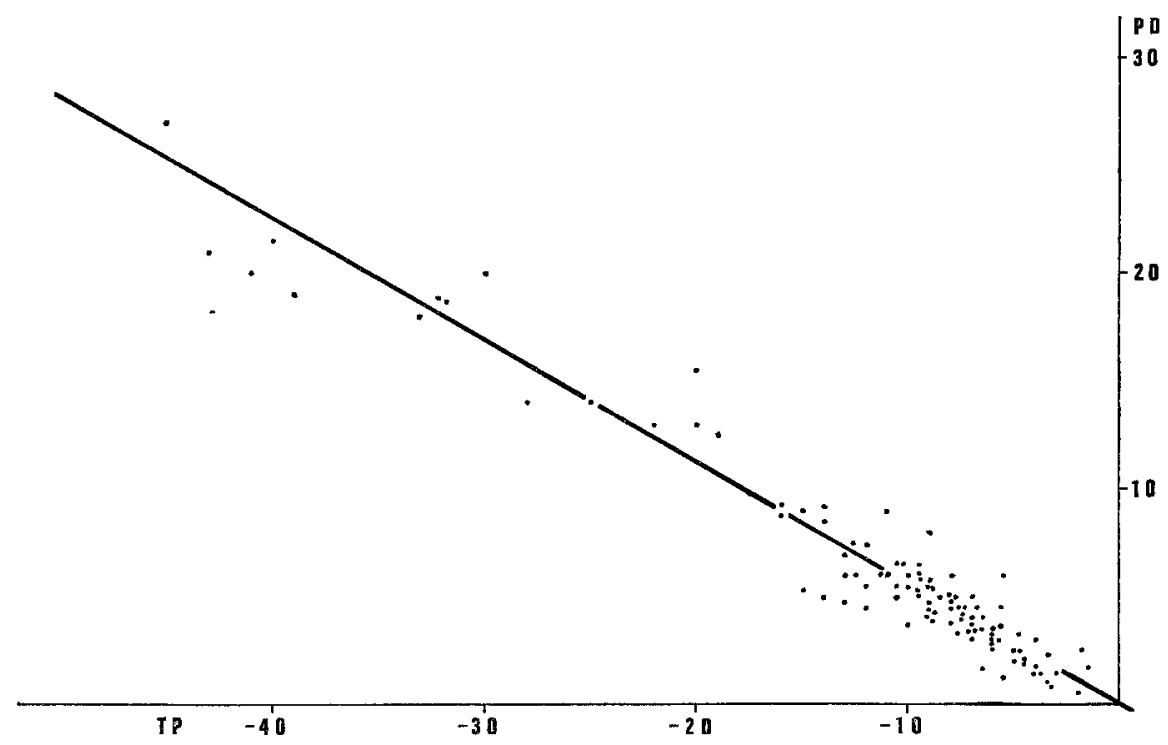

Fig. 2. Relationship between electrode tip potential and measured potential difference in lymphocytes. Regression line is given by the equation $\mathrm{PD}=-0.55 \cdot \mathrm{TP}+0.009$ which indicates that these cells have no membrane potential

lymphocytes have no membrane potential. The bright appearance of these cells under phase contrast observation $(400 \times$ magnification), their high membrane resistance and unchanged susceptibility to non-specific stimulation [10] showed their viability. The lack of a membrane potential was confirmed by using electrodes filled with physiological $\mathrm{NaCl}$ solution. These electrodes have virtually no tip potential $(-1 \mathrm{mV})$ when the tip is immersed in Eagle-Dulbecco medium and after insertion into resting lymphocytes potential differences of less than $0.5 \mathrm{mV}$ were registered. Measurements in cells of established lines (BICR/M1R-K; HeLa) with these $\mathrm{NaCl}$ electrodes resulted in membrane potentials of about $-50 \mathrm{mV}$, as found when using $3 \mathrm{M} \mathrm{KCl}$ electrodes with low tip potentials [7].

Another example of cells with a low membrane potential is the cellular slime mould Dictyostelium. Cells were kept in $16.7 \mathrm{mM}$ phosphate buffer and measurements with different electrodes revealed a linear relationship between the tip potential and the potential difference (Fig. 3). Computation of the regression line gave the equation

$$
\mathrm{PD}=-0.80 \cdot \mathrm{TP}-9.11
$$

with a correlation coefficient of -0.98 (31 electrodes). This equation indicates that these cells have a membrane potential of about $-9 \mathrm{mV}$.

Sekiya described a similar relationship between tip potential and potential difference with Ehrlich ascites tumor cells, but did not use it for the determination of the membrane potential [14].

Fig. 4 shows schematically the potential changes which occur upon insertion of an electrode into a cell and points out that the potential difference measured is always less than the actual membrane potential of the cell. $z$ represents the zero 


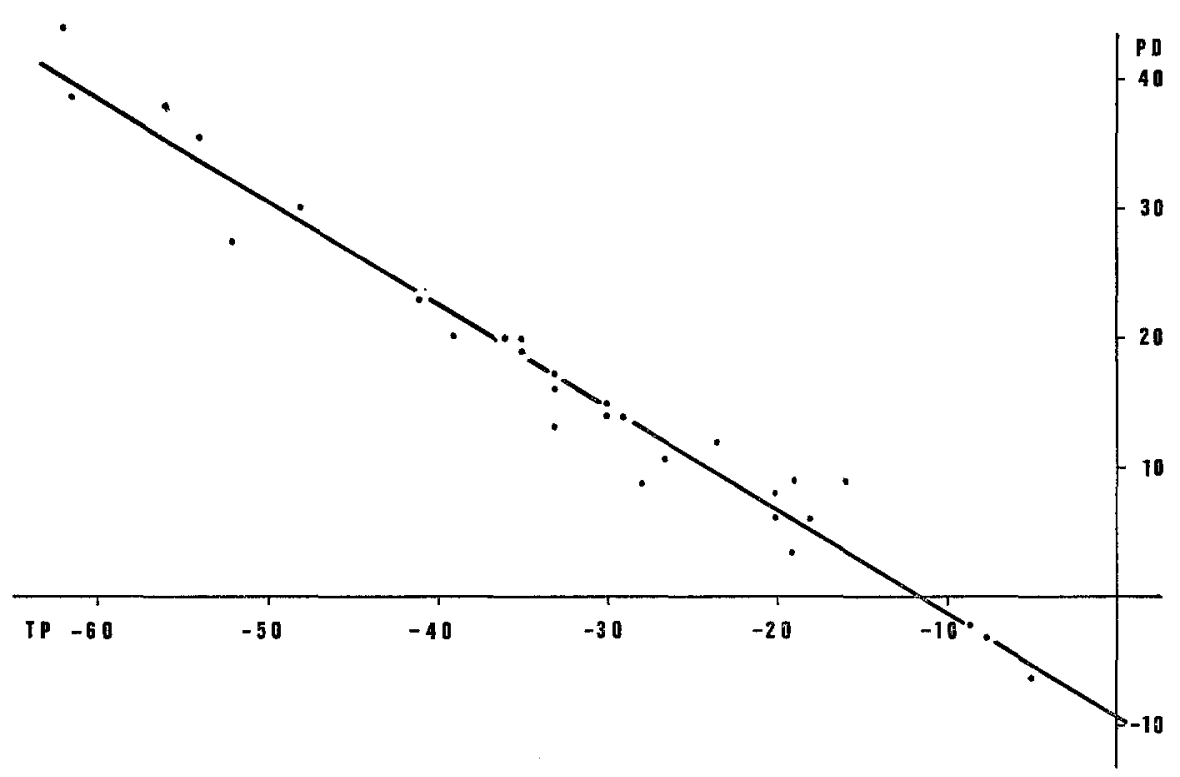

Fig. 3. Relationship between electrode tip potential and measured potential difference in the cellular slime mould Dictyostelium. Regression line is given by the equation $\mathrm{PD}=-0.80 \cdot \mathrm{TP}$

-9.11 which indicates that these cells have a membrane potential of about $-9 \mathrm{mV}$

potential obtained with a broken electrode and a Ringer-agar bridge as indifferent electrode. The tip potential of an introduced intact recording electrode is shown by $b$ which is also the baseline for the subsequent potential measurements indicated by the dashed line. When the electrode is inserted into a cell, the tip potential decreases, but at the same moment the membrane potential (MP) is also measured, so that only the potential difference (PD) is registered. If the indifferent electrode is also a fine-tipped glass microelectrode, the corresponding potential changes would occur with positive deflections for the tip potential and potential difference, as indicated by the dotted line. When the recording and indifferent electrodes are present together in the circuit as fine-tipped glass microelectrodes, as proposed by Bernhardt and Pauly [3], only the difference in the tip potentials of the two electrodes is recorded, whether in the medium or in a cell, as illustrated by the solid line. By carrying out such measurements it could be shown that the difference in the tip potentials with both electrodes in a cell was always less than with both electrodes in the medium.

An example of such a measurement is shown in Fig. 5. The cells used here were resting lymphocytes which have the advantage of lacking a membrane potential, so that only the tip potential changes are recorded. Introduction of intact recording and indifferent electrodes into the circuit resulted in the potential difference $\Delta \mathrm{TP}(-12 \mathrm{mV})$ which was the difference in the tip potentials of the two electrodes. Impalement of a lymphocyte with the indifferent electrode (tip potential $-9 \mathrm{mV}$ ) gave rise to a potential difference of about $-5.5 \mathrm{mV}$. Insertion of the recording electrode (tip potential $-21 \mathrm{mV}$ ) into the same lymphocyte produced a potential difference of about $+12 \mathrm{mV}$. With both electrodes thus situated in 


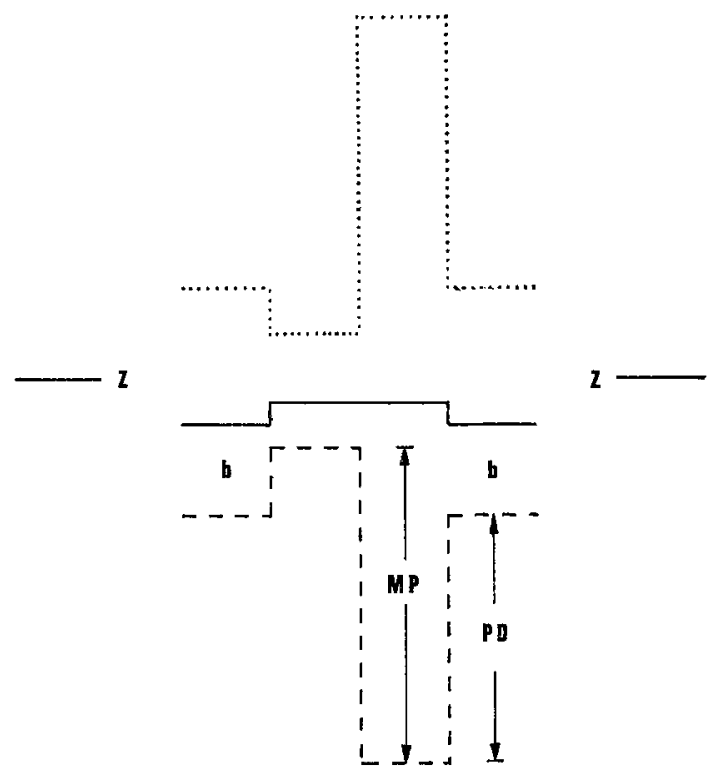

Fig. 4. Schematic drawing of the electrode tip potential change upon insertion of the electrode into a cell. For details see text

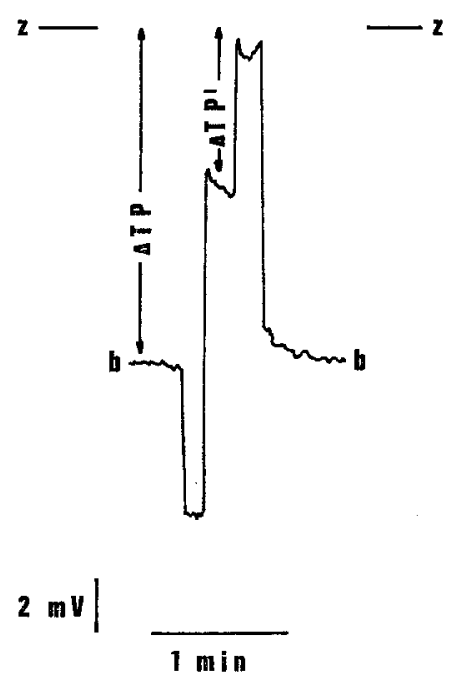

Fig. 5. Measurement of the tip potential difference between the recording and the indifferent electrode in medium $(\Delta \mathrm{TP})$ and in a lymphocyte $\left(\Delta \mathrm{TP}^{\prime}\right)$

the same lymphocyte, the difference in the tip potentials $\Delta \mathrm{TP}^{\prime}$ was about $-\mathbf{5 . 5} \mathrm{mV}$. The ratio $\triangle \mathrm{TP}^{\prime}: \triangle \mathrm{TP}$ provides a factor by which the tip potential of a glass mioroelectrode will decrease upon insertion into a cell; $1-\left(\Delta \mathrm{TP}^{\prime}: \Delta \mathrm{TP}\right)$ is the slope of the regression line. Removal of the indifferent electrode from the cell resulted in a 
potential difference of $+5 \mathrm{mV}$. In this situation only the recording electrode was inserted and, since this electrode had a higher tip potential, the measured potential difference was also higher, i.e. $+11.5 \mathrm{mV}$ measured with respect to the potential baseline (b). The potential baseline was again registered upon withdrawal of the recording electrode from the cell.

Similar experiments in which two microelectrodes were inserted into single cells were also performed with cells of the established lines BICR/M1R-K [7] and RE [9] which have membrane potentials of about $-50 \mathrm{mV}$. The ratio $\triangle \mathrm{TP}^{\prime}: \triangle \mathrm{TP}$ was found to be about 0.8 and thus indicated that the membrane potential of these cells can be determined with a relative error of less than $2 \%$ using electroded of tip potentials $<5 \mathrm{mV}$.

The different $\Delta \mathrm{TP}^{\prime}: \Delta \mathrm{TP}$ ratios in lymphocytes $(0.45)$ and in the establishes cell lines (0.8) are probably due to different intracellular ion strengths. The ratio for the slime mould Dictyostelium (0.2) cannot be compared in this context, since the cells were cultured in a different medium.

With Ehrlich ascites tumor cells, Bernhardt and Pauly [3] found a ratio of 0.63 for the tip potential change upon insertion into cells. The difference in the ratio for these cells, as compared to the established cell lines we used, may also be due to a different culture medium, so that the different values do not necessarily indicate a different intracellular ion strength.

In conclusion, electrodes with a wide range of tip potentials should be used for the determination of low cell membrane potentials. As we have demonstrated, the tip potential has a linear relationship to the measured potential difference upon cell impalement. The actual membrane potential thus can easily be calculated by linear regression.

Acknowledgements. The authors thank Dr. D. Malchow for providing the Diclyostelium discoideum and Dr. J. H. Peters for the preparation of the lymphocytes. The technical assistance of Miss Ivana Klein in the cultivation of the established cell lines is gratefully appreciated. This work was supported by the Deutsche Forschungsgemeinschaft.

\section{References}

1. Adrian, R. H.: The effect of internal and external potassium concentration on the membrane potential of frog muscle. J. Physiol. (London) 133, 631-658 (1956)

2. Barry, P. H., Diamond, J. M. : Junction potentials, electrode standard potentials and other problems in interpreting electrical properties of membranes. J. Membrane Biol. s, 93-122 (1970)

3. Bernhardt, J., Pauly, H.: Das Membranpotential von Ehrlich-Ascitestumorzellen. Biophysik 4, 101-112 (1967)

4. Frank, W., Ristow, H.-J., Schwalb, S.: Untersuchungen zur wachstumsstimulierenden Wirkung von Kälberserum auf Kulturen embryonaler Rattenzellen. Exptl. Cell Res. 70, $390-396$ (1972)

5. Gerisch, G.: Periodische Signale steuern die Musterbildung in Zellverbänden. Naturwissenschaften 58, 430-438 (1971)

6. Hausen, P., Stein, H., Peters, J. H.: On the synthesis of RNA in lymphocytes stimulated by PHA. Europ. J. Biochem. 9, 542-549 (1969)

7. Hülser, D. F.: Electrophysiologische Untersuchıngen an Säugerzellkulturen: Der Einfluß von Bicarbonat und $p \mathrm{H}$ auf das Membranpotential. Pflügers Arch. Eur. J. Physiol. 325, 174-187 (1971)

8. Hülser, D. F.: Ionic coupling between non-excitable cells in culture. In: Methods in cell physiol. 8 (1973) (Prescot, D. M., Ed.). New York-London: Academic Press (in press) 
9. Hülser, D, F., Frank, W.: Stimulierung von Kulturen embryonaler Rattenzellen durch eine Proteinfraktion aus fötalem Kälberserum. I. Elektrophysiologische Messungen an den Oberflächenmembranen. Z. Naturforsch. 26b, 1045-1048 (1971)

10. Hülser, D. F., Peters, J. H. : Contact cooperation in stimulated lymphocytes. II. Electrophysiological investigations on intercellular communication. Exptl. Cell Res. 74, 319-326 (1972)

11. Ling, G., Gerard, R. W.: The normal membrane potential of frog sartorius fibers. J. cellular Physiol. 34, 383-396 (1949)

12. Pfister, H., Pauly, H. : Einfluß von Diffusionspotentialen auf Membranpotential und Ionenaktivitätsmessungen in biologischen Systemen am Beispiel von KCl-RinderserumalbuminLösungen. Biophysik 6, 94-112 (1969)

13. Politoff, A. L., Socolar, S. J., Loewenstein, W. R.: Permeability of a cell membrane junction. Dependence on energy metabolism. $\mathfrak{J}$. Gen. Physiol. 53, 498-515 (1969)

14. Sekiya, T.: Strudies on the membrane potential of Ehrlich ascites tumor cells. Gann 63, $41-57(1962)$

15. Watts, D. J., Ashworth, J. M.: Growth of myxamoebae of the cellular slime mould Dictyostelium discoideum in axenic culture. Biochem. J. 119, 171-174 (1970)

Dr. D. F. Hülser

Max-Planck-Institut für Virusforschung

Abteilung für Physikalische Biologie

D-7400 Tübingen

Spemannstraße 35

Federal Republic of Germany 